\title{
The Construction of Integrated Information Portal Based on Innovative Development ---- A Case Study of Center for Studies of Information Resources of Wuhan University
}

\author{
Shengli Deng, Changping Hu \\ Center for the Studies of Information Resources of Wuhan University, \\ Wuhan,430072,China, victorydc@sina.com
}

\begin{abstract}
The construction of scientific research information platform is an important guarantee for innovative research. Based on scientific research oriented innovation and the change of user's need, this paper discusses the integrated function of information portal and its service orientation. On the basis of three level models and combining the construction of information portal of the center for studies of information resources of Wuhan University (CSIR), the paper constructs the integrated model of information portal for the scientific research institution and analyzes model's function and the realization process.
\end{abstract}

\section{Introduction}

Construction of innovative nation provides a good development opportunity for scientific research. In order to display the role of knowledge resources and based on information resources, taking the technology as the method, taking the innovation as a goal, the scientific research domain provides the information guarantee for the activities of scientific research by establishing information portal and integrating knowledge resources.

\section{Background and problems}

Each step of the scientific research can't leave the acquirement of information resources and obtaining abundant information is the premonition and insurance for

Please use the following format when citing this chapter:

Deng, S., Hu, C., 2007, in IFIP International Federation for Information Processing, Volume 251, Integration and Innovation Orient to L-Society Volume1, Wang, W. (Lds), (Boston: Springer), pp. 475-483. 
development of the scientific research. Surrounding the technical innovation, the scientific research reflected many development trends, such as inter-organization, inter-disciplinary [1]. The scientific research has such characteristics as wide range resources sharing, open research and widespread cooperation. The concrete performances are as follows: the quantity and the importance in the network academic information resource increase day by day[2]; the scientific research's informationazation, namely "e-science", which is the important characteristic different from research environment and scientific activity in the digital age. The academic information exchange system presents the distributional, dynamical characteristics[3]. Above the new states, users need integrated and personalized information service. In the process of informationazation, the information surplus and lack of knowledge causes the scientific research institution face several difficult problems as follows [4]:

(1) How to provide the simplest information for the communication between interior and exterior of the scientific research institution?

(2) How to realize knowledge resources solidification and sharing?

(3) How to realize the fusion between the exterior resources and interior resources?

(4) How to simplify and standard the complex workflow in the institution?

(5) How to make the staff seek and use resources effectively?

Surrounding these questions, the information portals of scientific research are not only information issuing, but also provide good service for users. The portal should transform from traditional website information issuing to interactive service platform[5]. The design goal of the portal integration system of scientific research organization is to develop an opening and expandable information user platform, and integrate information resources, tools and services under unified portal to provide service[6].

\section{Architecture of integrated information portal in research institution}

The portal integration system of research institution is a service system which takes information issuing, operation organizing, and resources service and so on. It is a working platform for integrating and processing information. This system will carry on the organic integration of the dispersed scientific research information through the science knowledge organization system, and will provide the diverse navigation and the resources retrieval, effectively guide the user to acquire knowledge, finally realize high efficiency information sharing[7]. Based on this theory, the paper proposed three levels design thought: The first will fully demonstrate the personnel, organization information of research institution and so on, to realize the information issuing function. The second will unify the research institution routine work, operation handling to the information portal platform. The third will integrate every kind of resource and service under one interface, provide the "one-stop service" to users [8].

Based on a three-tier model, we construct a model of integrated information portal system, as shown in figure 1. 
The figure takes portal system as user interface. Memory Repositories Layer includes all data and knowledge in CSIR. Data in the Repository is showed as XML format, and the design of its retrieval tools fully considers the content, metadata and the need for value-added services [9]. The knowledge administration Layer is composed with issuing platform, operating platform and knowledge service platform. Finally, demonstration Layer is responsible for transferring message to the terminal. The integrated thought of this model manifests in three aspects: resources integration, system integration and service integration [10].

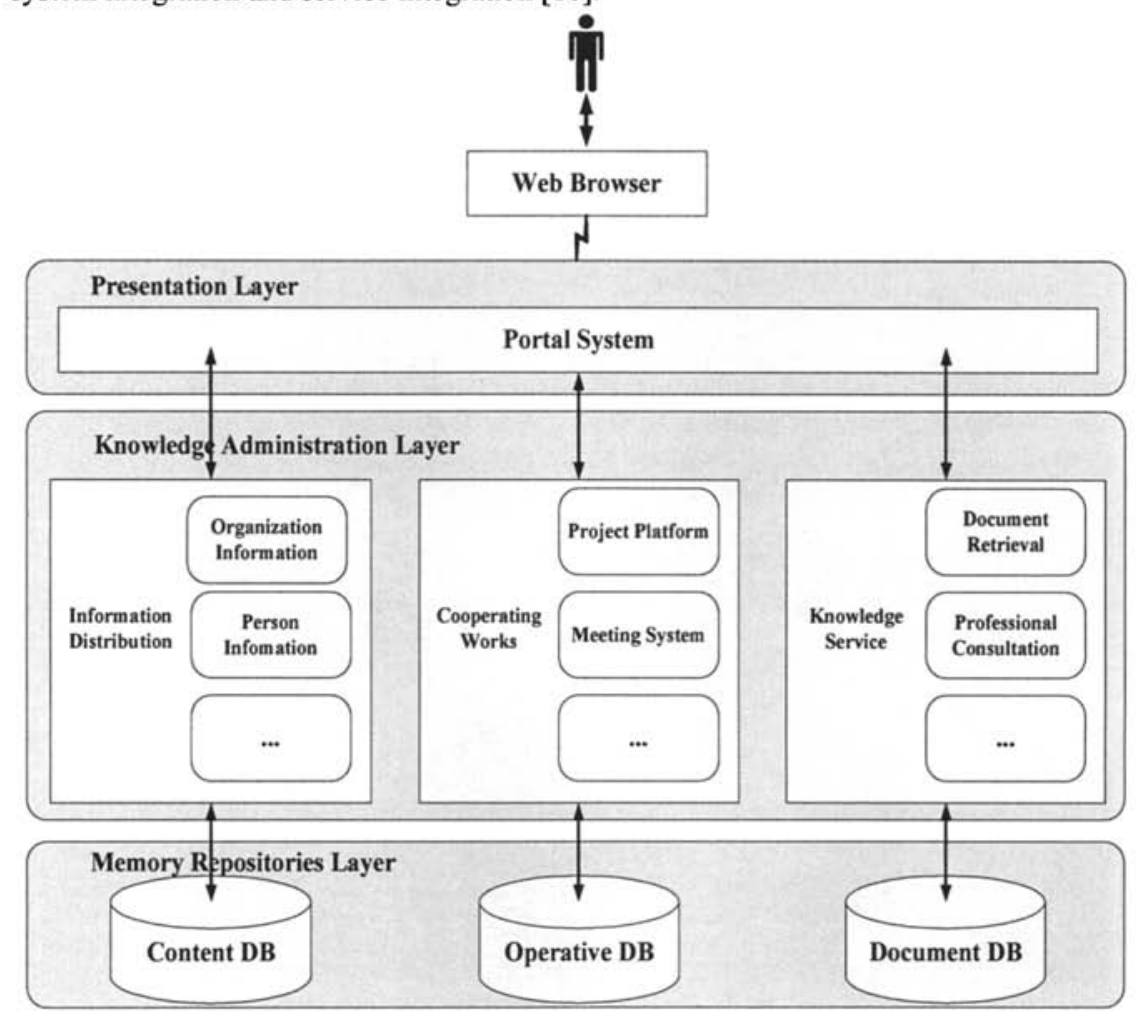

Fig. 1. Integrated system of information portal

\section{A case study-integrated information portal of CSIR}

According to three levels model, CSIR has established integration information portal for scientific research.

(1) The functional analysis of integrated portal of CSIR

The portal system of CSIR mainly includes the issuing platform in the front stage and management platform in the backstage. The issuing platform ought to fully integrate the information resource in the discipline domain; provide the service for the users as a unified portal. Concretely, the integrated portal of CSIR contains following three aspects: information communication; business platform; resources service. According to the above functional analysis, this paper constructs a frame as shown by figure 2 . 


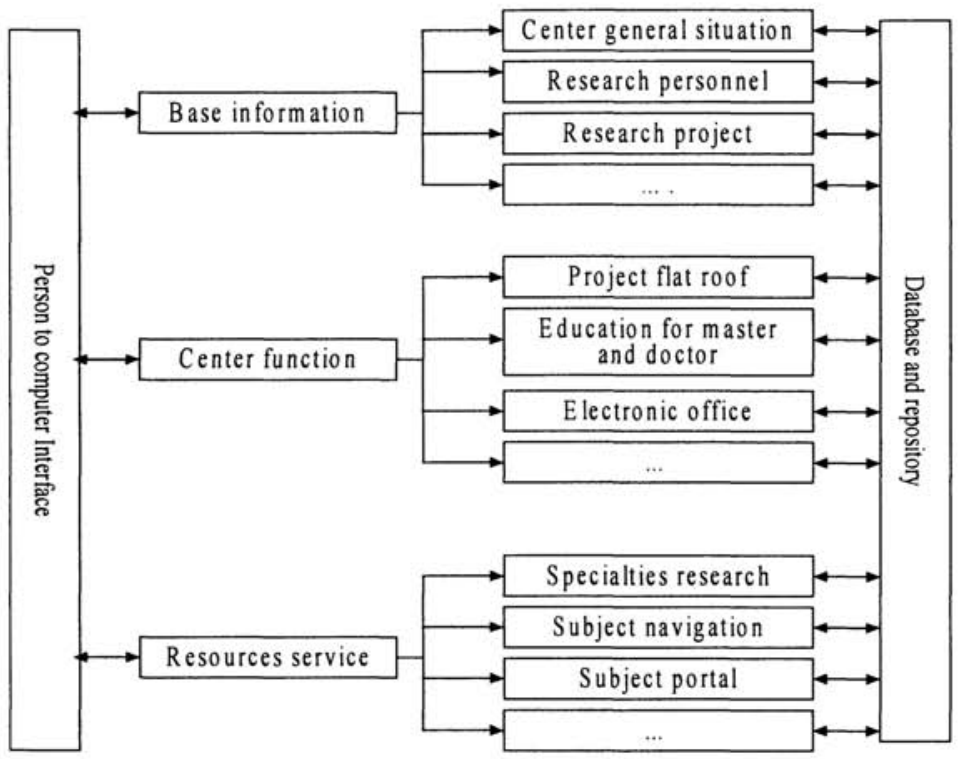

Fig. 2. Function frame of CSIR portal

CSIR Portal is constructed on the basis of the frame chart above. The interface is shown by figure 3 .

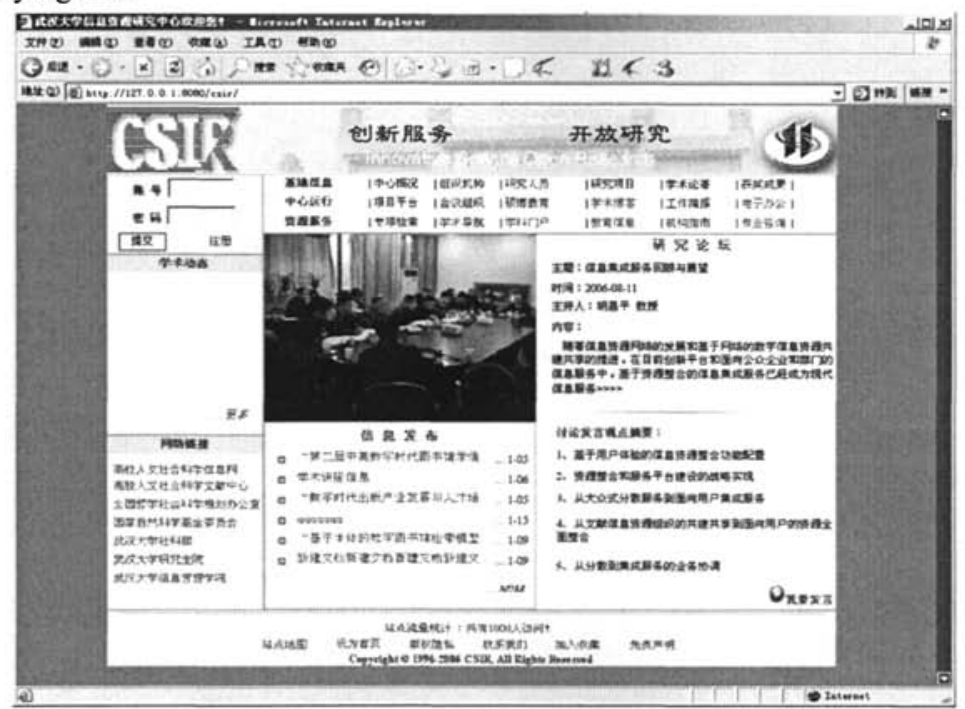

Fig. 3. Interface of CSIR portal

The module of "base information" fully reflects the information of teachers, achievements in CSIR. Surrounding the deployment of scientific research, users of 
CSIR are divided into three aspects, which are expert user, student user and administrator. After different users enter, they can do different things such as information browse, inquire, access and search according to their own administer right.

Business organizing function is embodied in "operation organizing" module. On one hand, the operation organizing of scientific research is deployed surrounding project, users can discuss some interesting projects with each other on the project platform, set up new project and research project, but any newly founded project should be strictly examined and approved by administrators. Along with the developing of project, scientific research users intercommunicate and share the research productions through project platform; meanwhile, those productions are finally formed into document. On the other hand, CSIR plays the role of training students. Scientific research is combined with teaching. Routines are miscellaneous. The management of scientific research is implemented through the portal platform, so that work efficiency and administration ability are improved.

"Resources service" module is faced to innovative demands, offering lots of services such as specialty search, subject navigation and specialty consultation to meet the users' demand of knowledge resources by resource integration and service integration, so that scientific research is thoroughly progressed [11].

(2) Key technology

Along with the rapid development of Informationazation, the enhancement of scientific research administration and service level is very important to selfdevelopment of scientific research institution, which would affect scientific research innovation and the enthusiasm of scientific research personnel. The CSIR portal system is based on the model of MVC and Struts, combining the lucene/XML technique, which can support full-text search.

(1) Technical realization based on MVC+Struts

The MVC design pattern, includes three types of objects: Model is the applied object, using for storage of the state and update of the view; View is an expressional form of the model-data manifestation; Controller abstracts user interaction and the application semantics mapping, and transfer user input to the application procedure, then according to user's input and context information to choose the appropriate view for demonstrating data.

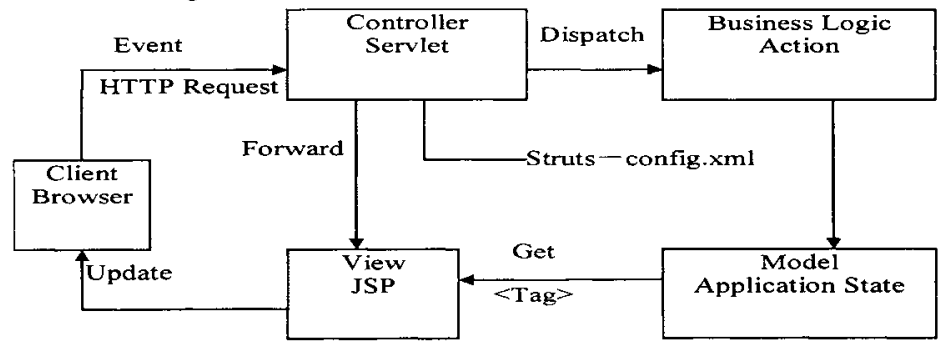

Fig. 4. MVC framework based on Struts

Struts is the MVC design pattern one kind of realization, it is a extremely outstanding application frame based on the MVC model, leaving user interface and transaction logic detached and causing the web level to be easy management and expansion, not only effectively enhanced developed efficiency of the system, but 
also enabled the system to have greater reusability, scalability and security. Figure 43 shows the realization MVC framework based on Struts.

MVC framework realization based on Struts has the following advantages: views.

A. When a model operates simultaneously the system can establish and use many

B. Because the returning data of the model does not bring any demonstrated form, thus these models can be directly applied to the interface.

C. Because an application is isolated by three-tier, therefore sometimes, as long as one tier of the application changes will be able to satisfy the changes of application.

(2) Based on lucene/XML technology full-text search

Lucene is not a completely full-text indexing application, while it is the full-text indexing engine tool kit, which is written with Java. It can be easily inserted into various applications aimed at the application of full-text indexing / search functions. Because XML has the characteristic of cross-platform, easy expression of the meaning, expandable, self-description and structure, content and performance separated, the emergence of XML has provided a lot of convenience for knowledge description, expression, storage and retrieval. The CSIR used the lucene/XML technology to construct the full-text retrieval system. Figure 5 is the journal literature retrieval system interface.

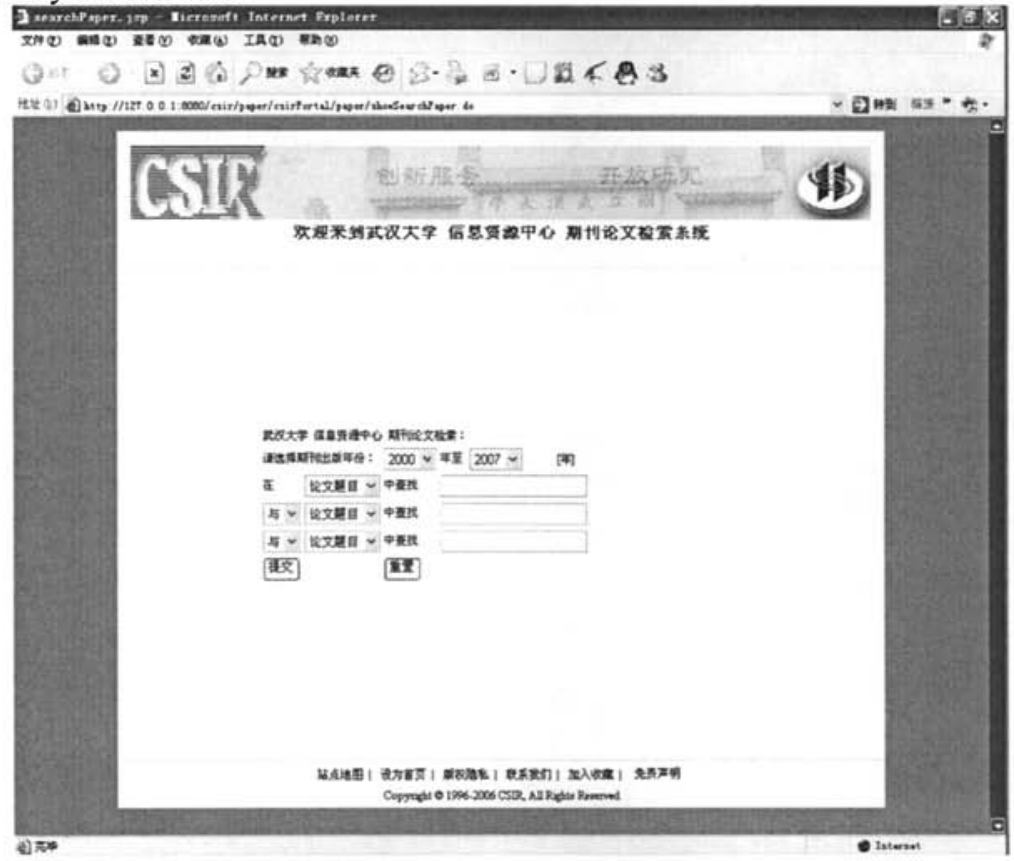

Fig. 5. Interface of periodical literature retrieval system

Each literature that includes in the retrieval system carries on the operation by $\mathrm{XML}$ document. The XML document is corresponding to the interface shown in figure 6 


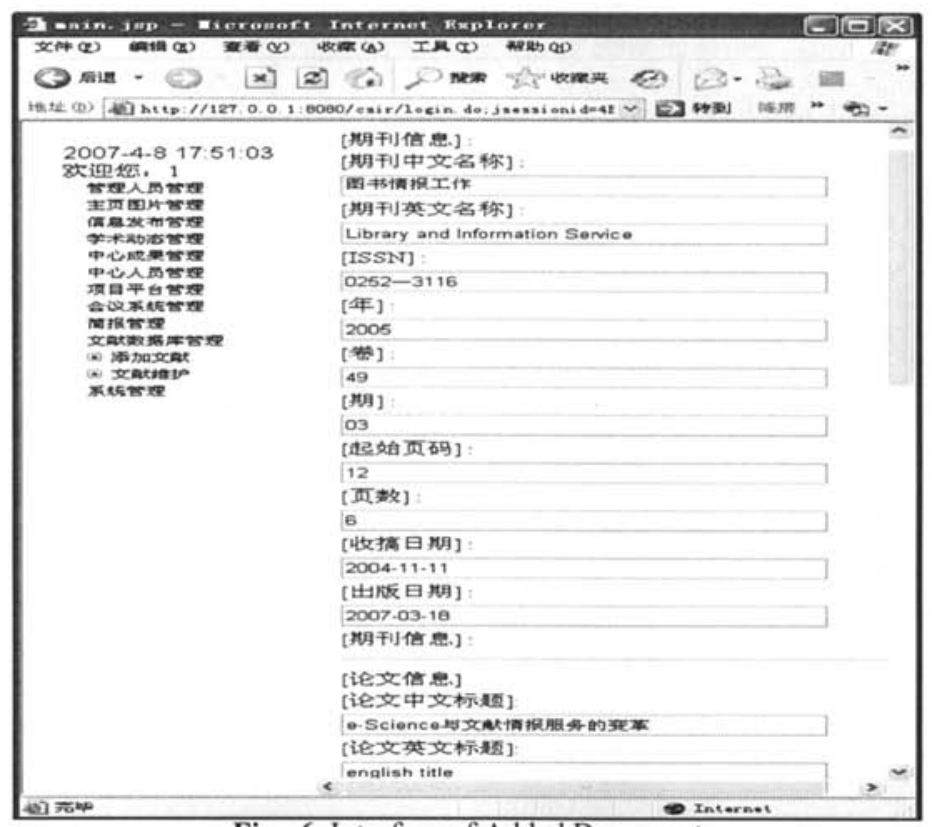

Fig. 6. Interface of Added Document

Every article input from background is written in the database by this interface. All relevant attributes of the documentation, such as author, literature title, etc. have a corresponding input frame. Submitted data is controlled by background and input to the XML file. The data corresponding to the attribute is automatically input to the label corresponding to XML file. Meanwhile, it's necessary to establish an index for the attributes to search by the interface provided by lucene as shown in figure 7, such as document title, the author, the units of the author. Meanwhile, lucene also provided logic inquiry interface that supports "and", "or" , "nor", which is very easy to use.

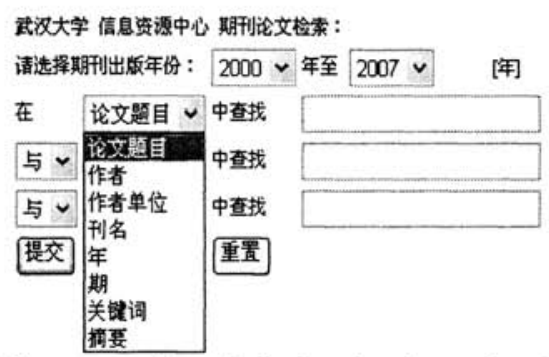

Fig.7. Literature attributes Index based on lucene interface 


\section{Conclusion}

CSIR has established a digital resource base and service platform through the construction of integrated information portal system. It will gradually establish a prefect digital information service system through the flexible integration of the resources, tools and systems in the application layer or user layer. Then it can effectively support knowledge application and knowledge innovation of the user. Of course, the development work of the portal is still going on and needs to be further improved. Further research is how to play the advantages of CSIR in resources and talents to upgrade information services level, which is the keystone for the portal construction in the future.

\section{Acknowledgments}

This paper is one of research results of project "The research on the system of knowledge information service of innovative nation" (number 06JZD0032) funded by Ministry of Education of the People's Republic of China

\section{References}

1. Jia jun, $\mathrm{Xu}$, et al. Enterprise Information Portal. Beijing: China Machine Press, 2004, pp. 10-11

2. Olga Danylova, et al. Information Portal "Our School": A Case Study of IT Introduction into Education in Ukraine. Proceedings of the IEEE International Conference on Advanced Learning Technologies (ICALT'04)

3. Fredric Landqvist, Dick Stenmark. Portal Information Integration and Ownership misfits:

A Case Study in a Tourism Setting. Proceedings of the 39th Hawaii International Conference on System Sciences - 2006

4. Andreas Billig, Jan Gottschick, Kurt Sandkuhl. Evolution of Web Computing Systems: Experiences from Web-Portal Projects. Proceedings of the 2005 3lst EUROMICRO Conference on Software Engineering and Advanced Applications (EUROMICRO-SEAA '05)

5. Thomas Puschmann, Rainer Alt. Process Portals - Architecture and Integration. Proceedings of the 37th Hawaii International Conference on System Sciences - 2004

6. Rainer Weinreich, Thomas Ziebermayr, Enhancing Presentation Level Integration of Remote Applications and Services in Web Portals. Proceeding of the 2005 IEEE

International Conference on Services Computing (SCC'0S).

7. HIROAKI YUASA, et al. Development of User-friendly Supercomputing Portal in Bio Research Field. Proceedings of the First International Conference on e-Science and Grid Computing (e-Science' 05)

8. Yongjin Zhang, Hongqi Chen, and Jiancang Xie. Study on Intelligent Information Integration of Knowledge Portals. 3614, 2004, pp. 1136- 1141

9. Fredric Landqvist, Dick Stenmark, "Portal Information Integration and Ownership Misfits: A Case Study in a Tourism Setting", Proceedings of the 39th Annual Hawaii International Conference on System Sciences (HICSS'06) Track 8, 2006,pp. 173. 
10. Hsieh, et al. An Integrated Healthcare Enterprise Information Portal and Healthcare Information System Framework. Engineering in Medicine and Biology Society, 2006. EMBS '06. 28th Annual International Conference of the IEEE, pp.4731-4734

11. Fengchun Zhu, et al. A Framework to Develop A University Information Portal. Proceedings of International Conference on Information Acquisition, 2004,pp.506- 509 